\title{
Acquired hypertrichosis lanuginosa
}

INSERM

\section{Source}

INSERM. (1999). Orphanet: an online rare disease and orphan drug data base. Acquired hypertrichosis lanuginosa. ORPHA:2221

Acquired hypertrichosis lanug inosa is a rare cutaneous paraneoplastic disease characterized by the presence of excessive lanugo-type hair on the glabrous skin of face, neck, trunk and limbs that can be associated with additional clinical features such as burning glossitis, papillary hypertrophy of the tongue, diarrhea, dysgeusia, and/or weight loss. It is associated with lymphoma or cancer of the gastrointestinal system, urinary tract, lung, breast, uterus or ovary. 